\title{
LAS FUENTES DEL DERECHO EN EL TRATADO POR EL QUE SE ESTABLECE UNA CONSTITUCIÓN PARA EUROPA $^{1}$
}

\author{
JORGE ALGUACIL GONZÁLEZ-AURIOLES \\ Profesor Ayudante UNED
}

ÍNDICE

1. Introducción: presupuestos metodológicos.

2. La regulación de las fuentes previa al Tratado por el que se establece una Constitución para Europa.

3. La regulación de las fuentes en el Tratado por el que se establece una Constitución para Europa.

4. A modo de conclusión

\section{INTRODUCCIÓN: PRESUPUESTOS METODOLÓGICOS}

La disciplina de las fuentes del Derecho, lejos de ser una cuestión estrictamente técnica o jurídica, encierra un fuerte componente político. Como señala de Cabo, «esta materia está bien prendida en la realidad, en la realidad histórica, desde donde cobra significado y en la realidad política respecto de la que cumple importantes funciones y a la que en buena medida expresa» ${ }^{2}$. Si el proceso de integración europea interpela al constitucionalismo clásico asentado en la categoría Estado nación, ésto se evidencia específicamente en la materia de las fuentes del Derecho. Su evolución, en definitiva, es el reflejo de los cambios

1 Desarrollo en este artículo algunas ideas anticipadas en mi libro La directiva comunitaria desde la perspectiva constitucional (Madrid: Centro de Estudios Políticos y Constitucionales, 2004) atendiendo a la regulación definitiva del Tratado por el que se establece una Constitución para Europa

2 DE CABO, C, «Las fuentes del Derecho. Apunte sistemático», Contra el Consenso. Estudios sobre el Estado Constitucional y el constitucionalismo del Estado social, México: Universidad Autónoma de México, 1997, pág. 286 
de la integración, algunos de ellos de relevancia constitucional ${ }^{6}$. Las novedades que presenta en materia de fuentes son notables y obedecen además a los trabajos de un grupo específico en el seno de la Convención. Este grupo, denominado Simplificación y presidido por Giuliano Amato, vicepresidente de la Convención, pretende paliar las deficiencias del sistema de fuentes de los Tratados y aproximarlo al propio del Estado constitucional. Si bien, como veremos, tal objetivo sólo se cumple parcialmente, lo cierto es que la regulación definitiva varía respecto a su regulación en los vigentes Tratados. El contraste se hará mejor tras ofrecer una panorámica general sobre la regulación de las fuentes del Derecho previa al Tratado por el que se establece una Constitución para Europa ${ }^{7}$.

\section{LA REGULACIÓN DE LAS FUENTES PREVIA AL TRATADO POR EL QUE SE ESTABLECE UNA CONSTITUCIÓN PARA EUROPA}

\subsection{LAS FUENTES DEL DERECHO}

No se diferencian las fuentes en Europa por el centro de producción, sino por su efica$\mathrm{cia}^{8}$. Se prescinde así del fundamento orgánico en el que apoyar cualquier jerarquía. De la lectura del artículo 249 TCE se infiere, en primer lugar, que entre las fuentes que regula rige exclusivamente una relación competencial. Ello rompe con cierta tradición de nuestros Estados constitucionales, por más que en el actual constitucionalismo el principio jerárquico haya sido modulado por el competencial hasta el extremo de hacerlo primar en ciertos supuestos 9 . La perspectiva adquiere en el nuevo orden una relevancia especial; para García Roca, la transferencia por los Estados de competencias a la Unión Europea «abre la puerta al principio de competencia como criterio de relación entre ordenamientos» ${ }^{10}$. Si la cooperación

3 El proceso de integración europea, tradicionalmente estudiado por otras disciplinas, adquiere una importancia creciente para la doctrina constitucional, DÍEZ-PICAZO, L.M, Constitucionalismo en la Unión Europea, Madrid: Cívitas, 2002, LÓPEZ PINA, A; GUTIÉRREZ GUTIÉRREZ, I, Elementos de Derecho Público, Madrid: Marcial Pons, 2002. No obstante, no sólo ha prestado escasa importancia la dogmática europea a las fuentes del Derecho como ha observado BOGDANDY, A; BAST, J; ARNDT, F, Tipología de los actos en el Derecho de la Unión Europea. Análisis empírico y estructuras dogmáticas en una presunta jungla», Revista de Estudios Políticos, enero - marzo, 2004. Tampoco han abundado las investigaciones de la doctrina interna sobre la materia; cabe citar, no obstante, la polémica obra de REQUEJO PAGÉS, J.L, Sistemas normativos. Constitución y Ordenamiento. La Constitución como norma sobre la aplicación de las normas, Madrid: Mc Graw Hill, 1995

4 Existe numerosa bibliografía sobre el particular. Numerosos autores niegan la existencia de una Constitución para Europa por la sencilla razón de que no existe un pueblo europeo; baste citar al efecto KIRCHHOF, P, «Europäische Einigung und der Verfassungsstaat der Bundesrepublick Deutschland», ISENSEE, E (ed), Europa als politische Idee und als rechtliche Form, 1 Aufl, 1993. Ahora bien, la mitificadora apelación directa al pueblo no puede desconocer el carácter eminentemente representativo de los procesos constituyentes. Lo cierto es que el poder constituyente no descansa necesariamente en una identidad prepolítica, sino especialmente en la voluntad expresada por los ciudadanos en el marco de procesos democráticos institucionalizados, cfr. al respecto, la polémica entre Grimm y Habermas. Las reflexiones de GRIMM, D, «¿Necesita Europa una Constitución?, Debats n 55 , marzo, 1986, págs. 4 - 19, son contestadas por HABERMAS, J, «Observaciones a «¿Necesita Europa una Constitución?m», Debats n 55 , marzo 1996, págs. 23 y 24 
constitucionales y va unida, de manera muy sensible, a las transformaciones sociales y políticas que marcan el ritmo del constitucionalismo. Las actuales modificaciones del orden constitucional estatal se han de reflejar específicamente, pues, en materia de las fuentes.

Al menos desde el Tratado de Mastrique, la doctrina constitucional toma conciencia de la importancia del proceso de integración y de su incidencia en el sistema de fuentes interno. La sentencia del Tribunal Constitucional Federal alemán sobre el Tratado de Mastrique es básica para comprender la realidad. Hace notar la importancia del nuevo Derecho basándose en unas estimaciones del entonces presidente de la Comisión, Jaques Delors. Cerca del $80 \%$ de la legislación económica interna trae causa del Derecho comunitario y cerca del $50 \%$ de la legislación restante encuentra también su origen en la legislación de Bruselas. Se ha de convenir, pues, que la teoría de las fuentes del Derecho y el propio Ordenamiento nacional no pueden ser por más tiempo analizados sin atender a la centralidad de unas fuentes decisivas para la conformación del actual Ordenamiento Jurídico. La relación entre el proceso europeo de creación de Derecho y el Derecho nacional se convierte un asunto decisivo para la situación constitucional en ciernes, por más que en un principio se considerara materia de segundo orden ${ }^{3}$.

La integración europea sufre un nuevo punto de inflexión con el proceso desencadenado tras el Consejo de Laeken. Abre una nueva etapa en la construcción europea que ha culminado con la aprobación del Tratado por el que se establece una Constitución para Europa. Ciertamente, surgen dudas sobre el carácter constitucional del nuevo Tratado; a la discusión sobre si existe un pueblo europeo ${ }^{4}$, se une al menos una reserva de gran calado. La propia extensión y detalle del Tratado parecen alejarlo de las Constituciones estatales; la tercera parte, especialmente detallada y extensa, trata de las políticas y el funcionamiento de la Unión, sistematizando al efecto el minucioso contenido de los antiguos tratados y, con ello, coartando desproporcionadamente el desenvolvimiento de la Unión conforme a la libre voluntad democráticamente formada por sus instituciones ${ }^{5}$.

En cualquier caso, el nuevo Tratado incorpora importantes avances en el desarrollo

5 Ciertamente, su aprobación por medio de un Tratado no la aleja irremisiblemente de la noción clásica de Constitución; la diferencia entre los tratados internacionales y las constituciones es bastante difusa. Lo que verdaderamente importa «no es tanto la denominación del documento, cuanto su modo de elaboración y aprobación, los poderes otorgados a las instituciones», DÍEZ-PICAZO, L.M, Constitucionalismo de la Unión Europea, Madrid: Cívitas, 2002, pág. 106. Pero quizá es precisamente su contenido el que lo aleja de una Constitución, cfr. LÓPEZ PINA, Europa. Un proyecto irrenunciable. La Constitución para Europa desde la teoría constitucional, Madrid: Dykinson, 2004, págs. 220 ss.

6 El Parlamento Europeo elabora un resumen del Tratado adoptado por el Consejo de Bruselas los días 17 y 18 de junio de 2004. Al comienzo destaca su significación: «Dan prueba de su alcance constitucional su inicio, con el enunciado de los valores en que se fundamenta la Unión (art. 2); la inclusión de la Carta de los Derechos Fundamentales en su integridad (parte II); la definición de las condiciones de pertenencia a la Unión (incluidas las de retirada voluntaria de la misma), y los símbolos de la Unión (bandera, himno, etc; art. I-6 bis)

7 El Tratado por el que se establece una Constitución para Europa trae causa de los trabajos realizados por la Convención sobre el Futuro de Europa y las discusiones acaecidas en las sucesivas Conferencias Intergubernamentales celebradas bajo presidencia italiana e irlandesa, cfr. ALGUACIL GONZÁLEZAURIOLES, J, El proceso de elaboración del Tratado por el que se establece una Constitución para Europa, Madrid: Boletín Oficial del Estado y Centro de Estudios Políticos y Constitucionales, 2005

8 Todo ordenamiento complejo impone al poder originario, una vez constituido, la creación de nuevos centros de producción jurídica para satisfacer las necesidades de regulación, BOBBIO, N, Teoría general del Derecho, Madrid: Editorial Debate, 1991, pág. 168 
menos en principio, la aprobación de normas nacionales en la materia que no se reduzcan a asegurar su propia ejecución ${ }^{20}$. A su vez, y merced al principio de primacía del Derecho europeo, se impone por encima de la ley e incluso de la Constitución; representa en su mayor amplitud la hegemonía del orden europeo sobre el estatal. La mayor parte del Derecho que adoptan las instituciones europeas adopta la forma de reglamento ${ }^{21}$.

La directiva se configura por oposición al reglamento, evidencia una forma distinta de concebir el Derecho. Sus destinatarios son exclusivamente los Estados miembros, que se encuentran obligados a incorporarla en el respectivo ordenamiento nacional. Obliga sólo en cuanto al resultado, lo que significa que no puede imponer directamente obligaciones y derechos a los particulares, como el reglamento. Carece, pues, del carácter completo, tanto formal como material, que caracteriza a los reglamentos. El único elemento vinculante que se desprende de la propia regulación del Tratado es el resultado a alcanzar, aunque tal circunstancia podría ser insuficiente para asegurar la condición de norma jurídica a la directiva. Si no existe un plazo de ejecución para el Estado miembro, éste podría incluso prolongar su incorporación sine die, impidiendo con ello que pudiese desplegar efectos jurídicos. La imposición de un plazo, aun cuando no venga recogida en el Tratado, parece ser un requisito para considerar la directiva como norma jurídica; así lo reconoció desde el comienzo la doctrina y el Tribunal de Justicia. El problema surge, sin embargo, al determinar los efectos jurídicos que debe producir el incumplimiento del plazo señalado.

Las decisiones no pueden considerarse fuentes del Derecho: son actos administrativos singulares que entran en vigor mediante su notificación; las decisiones adoptadas con arreglo

9 CRISAFULLI «Gerarchia e competenza nel sistema costituzionale delle Fonti», VV.AA, Studi in onore di Guido Zanobini, Vol II, Milán: Giuffré, 1965, pág. 199

10 GARCÍA ROCA, J, «Estatalidad versus soberanía», PÉREZ CALVO, A (coord), Estado, nación y soberanía (problemas actuales en Europa), Madrid: Senado, 2000, pág. 306.

11 PORRAS NADALES, A.J, «Estado postsocial e integración europea», APARICIO PÉREZ, M.A, Derechos Constitucionales y Formas Políticas. Actas del Congreso sobre derechos constitucionales y Estado Autonómico, Barcelona: Cedecs, 2001, pág. 685

12 Infiere así BOBBIO la estructura jerárquica del ordenamiento a partir de la propia unidad que se ha de predicar del mismo, Teoría general del Derecho, Madrid: Editorial Debate, 1991, pág. 173.

13 Sobre la relación entre principio democrático y principio de jerarquía, Cfr. DE CABO, C, Sobre el concepto de ley, Madrid: Trotta, 2000, págs. 29 ss.

14 Se trata de un número abierto de actos de naturaleza un tanto oscura y de efectos jurídicos indeterminados; los únicos requisitos que deben cumplir es tener origen institucional y encuadrarse en ámbitos de competencia comunitaria. Así ocurre, por ejemplo, con las orientaciones, término que aparece en materia de coordinación económica (artículo 99 TCE), de política de empleo (artículo 128 TCE) y de redes transeuropeas (artículo 155 TCE); o también el programa marco utilizado en materia de investigación (artículo 166 TCE) o los programas de acción en el medio ambiente (artículo 175 TCE). También existen actos denominados decisiones pero que distan de ser la figura recogida en el artículo 249 TCE por ejemplo, la Decisión relativa al sistema de recursos propios de la Comunidad, la Decisión por la que se establecen los procedimientos para el ejercicio de las competencias de ejecución atribuidas a la Comisión (Decisión Comitología) (artículo 202 TCE) o las decisiones basadas en el artículo 308 TCE. También regula el Tratado las denominadas decisiones de aplicación que parecen ser normas de ejecución, por ejemplo, las contempladas en los artículos 148 TCE y 162 TCE relativas, respectivamente, al Fondo Social Europeo y al Fondo Europeo de Desarrollo Regional.

15 Se trata de prácticas o costumbres europeas que se han ido consolidando. Los acuerdos inter-institucionales, manifestación práctica del principio de cooperación leal entre instituciones, las conclusiones y resoluciones del Consejo Europeo, que tiene carácter más político que jurídico, pero que pueden afectar a los procedimientos legislativos, las resoluciones y conclusiones del Consejo, que sólo tienen valor político pero que no están totalmente exentas de efectos jurídicos (tienen valor para interpretar los actos jurídicos, como ha reconocido el Tribunal de Justicia), las declaraciones de 
entre ordenamientos hace que no puedan considerarse por más tiempo de forma autónoma, exige a su vez, como observa Porras Nadales ${ }^{11}$, superar los marcos jerárquico-competitivos preexistentes. Mas no implica que la jerarquía haya de perder su papel configurador en el sistema de fuentes del nuevo orden como elemento racionalizador e instrumento necesario para reducir su complejidad a unidad ${ }^{12}$; y especialmente como elemento que asegure la legitimación democrática de configuración de la voluntad europea ${ }^{13}$. La particular complejidad del orden europeo impone tal principio; su ausencia resulta especialmente significativa.

El Tratado de la Unión Europea, reformado por última vez en Niza, regula diferentes figuras jurídicas que adscribe, a su vez, a los diferentes pilares de la Unión. Las instituciones europeas se expresan también a través de los denominados actos atípicos; algunos de ellos regulados en el Tratado ${ }^{14}$, otros surgidos de prácticas comunitarias no reguladas en los Tratados ${ }^{15}$. El primer pilar lo forma el Tratado de la Comunidad Europea; el Derecho que emana de este Tratado es el Derecho comunitario y las fuentes jurídicas de que dispone son el reglamento y la directiva (artículo 249 TCE) ${ }^{16}$.

El reglamento, como es conocido, tiene un alcance general, es obligatorio en todos sus elementos y directamente aplicable en cada Estado miembro. Se configura como un medio privilegiado al servicio de la integración. Lo califica Bleckmann como el auténtico acto legislativo (Gesetzgebungsakt) de la Comunidad Europea ${ }^{17}$. Se caracteriza por la indeterminabilidad de sus destinatarios, esto es, sus prescripciones son de carácter general; y es una norma abstracta, referida por tanto a un objeto indeterminado. No obstante, detrás de tales características puede esconderse en muchos casos una regulación específica. Ello puede explicarse desde la insuficiencia que se predica incluso de la ley general y abstracta ${ }^{18}$ en el propio Estado constitucional y, en particular, en el régimen constitucional español ${ }^{19}$. Desde que surge de las instituciones comunitarias es perfecta en grado máximo; impide con ello, al

los Estados miembros incluidas en las actas o en las conclusiones del Consejo, que no tienen efectos jurídicos, las declaraciones que las instituciones adjuntan a algunos actos jurídicos, que tienen un valor meramente declarativo

16 El segundo pilar lo forma la Política Exterior y de Seguridad Común (Título V TUE). El Derecho que emana de este pilar se caracteriza por su falta de fuerza de obligar, podría encuadrarse dentro de lo que se llama soft law. El tercer pilar está formado por las disposiciones relativas a la cooperación policial y judicial en materia penal (Título VI TUE). Surge originariamente con la exclusiva intención de aproximar legislaciones pero ha ido adquiriendo cada vez más importancia.

17 BLECKMANN, A. Europarecht. Das Recht der Europäischen Union und der Europäischen Gemeinschaften, op. cit, pág. 161

18 Debe distinguirse entre la generalidad y abstracción. Mientras la primera se refiere al sujeto y, por lo tanto, se opone a norma individual, la segunda se refiere al objeto, y se opone a norma concreta. La abstracción, así, y como explica MONTILLA MARTOS, se encuentra sumida en la generalidad, Las leyes singulares en el ordenamiento constitucional español, Madrid: Cívitas, 1994, págs. 40 ss.

19 MONTILLA MARTOS, J. A., Las leyes singulares en el ordenamiento constitucional español, op. cit, págs. 52 SS.

20 Se integra en los ordenamientos jurídicos nacionales a partir de su publicación en el Diario Oficial de las Comunidades Europeas, desplegando su eficacia desde la fecha que él mismo fije o, a falta de ella, a los veinte días de su publicación (artículo 254 TCE). Los ordenamientos nacionales, a lo sumo, podrán desplegar una actividad administrativa, en orden a asegurar su aplicación.

21 Así lo hace notar BOGDANDY, A; BAST, J; ARNDT, F, «Tipología de los actos del Derecho de la Unión Europea. Análisis empírico y estructuras dogmáticas en una presulta jungla», op. cit, págs. 22, 23 


\subsection{LA INCIDENCIA DE LA CONCEPCIÓN DEL DERECHO EN LAS FUENTES}

$\mathrm{El}$ orden europeo, en consonancia con el propio enfoque funcionalista con que se diseñó, es un régimen dinámico, orientado por unos objetivos que realiza gradualmente. Los objetivos de la Unión recogidos en el artículo 2 TUE orientan la interpretación y aplicación de todas las disposiciones comunitarias. Se articula una cláusula de cierre del sistema competencial que permite que «sea la propia Comunidad la que vaya precisando los límites efectivos de sus ámbitos competenciales» ${ }^{30}$. El artículo 308 TCE atribuye a la Comunidad la facultad de irrogarse competencias en función de objetivos ${ }^{31}$, compensa así la limitación de poder que encarna el principio de las limitadas habilitaciones especificas ${ }^{32}$. De este modo, la delimitación del ámbito de cooperación a través de los Tratados se revela como una delimitación normativa débil o dúctil ${ }^{33}$ y la interferencia del Derecho comunitario sobre el sistema de fuentes constitucionalmente configurado aparece como virtualmente plena. Tal delimitación teleológica de las competencias, si bien resulta coherente con el planteamiento de desarrollo gradual de la Comunidad, parece apartarse de los clásicos criterios que operan en esta materia en nuestros Estados constitucionales. Las «normas competenciales dotadas de un componente dinámico del Derecho comunitario están al servicio de la realización gradual de los fines de la Comunidad; las normas de competencia de estructura estática de nuestras Constituciones tienen como fin la transparencia y la moderación del poder» ${ }^{34}$. «Desde este trasfondo la dinámica del proceso de integración se escapa de las manos ${ }^{35}$. Schoch lo ha denominado unidimensionalidad material del Derecho comunitario ${ }^{36}$.

Las normas europeas, además, son interpretadas por el Tribunal de Justicia exclusivamente al servicio de una mayor integración; sobrevalora la interpretación teleológica ${ }^{37}$. Liga los objetivos de la Unión y el denominado efecto útil ${ }^{\beta}$ de este ordenamiento con su necesaria aplicación uniforme. Hace uso del método comparado para extraer principios jurídicos de los ordenamientos de los Estados, pero inmediatamente los autonomiza y los utiliza para su objetivo integrador ${ }^{39}$. El resultado es una lectura del Derecho únicamente desde la perspectiva del logro de la unidad europea ${ }^{40}$.

Esta concepción del Derecho y la consiguiente actividad del Tribunal de Justicia alienta, de un lado, el desarrollo de los denominados actos atípicos. Se caracterizan, como hemos visto, por su indefinición, que los adecúa perfectamente a la funcionalidad que precisa el Derecho comunitario. Contribuye además a diluir las características y la naturaleza de ciertas fuentes del Derecho que pueden frenar el ritmo de la integración; es el caso

22 Las recomendaciones y los dictámenes carecen de fuerza de obligar. No obstante, pueden gozar de una cierta capacidad de influir en el devenir europeo, poseen ciertos efectos políticos. Se trata al menos de comunicados oficiales de la Comunidad, respecto de los que no es de excluir un cierto vínculo con el mandato de lealtad (artículo 10 TCE)

23 Existe reserva de directiva en los artículos 44 TCE, 47 TCE, 52 TCE, 94 TCE

24 Así se da en los artículos del Tratado de la Comunidad Europea 12.2, 18.2, 49, 141.3, 152.4, 133.2, 179, $190.4,212,269,272,104.14,107.5,161,175.3$

25 A modo de ejemplo, cfr. artículos 37.2 TCE, 40 TCE, 83 TCE

26 Este precepto otorga a la Comisón la facultad para ejecutar las disposiciones del Consejo, pero, a su vez, dispone de un poder de decisión propia y participa en la formación de los actos del Consejo y del Parlamento europeo. De la lectura conjunta de estas competencias cabe inferir la capacidad de la Comisión para desarrollar normas del Consejo, modulando a su vez su propio contenido

27 El Consejo atribuirá a la Comisión las competencias de ejecución que establezca. Mas tales competencias pueden ser sometidas por el propio Consejo a determinadas condiciones. 
al procedimiento de codecisión (artículo 251 TCE) se publican en el Diario Oficial de la Unión Europea (artículo 254 TCE). Si bien son actos obligatorios en todos sus elementos para todos sus destinatarios, sólo vinculan a los individuos o a los Estados a los que van dirigidos. Inciden en la esfera jurídica de los individuos y crean en ellos derechos y obligaciones, mas carecen de la generalidad característica, al menos en teoría, de las fuentes del Derecho. En el supuesto de ir dirigidas a un individuo rige el principio del efecto directo del Derecho europeo; si se dirigen al Estado, parece que no debería darse la eficacia directa de la norma con respecto a los particulares. La inexistencia del principio jerárquico impide que estos actos se encuentren subordinados a una disposición jurídica que, al menos en teoría, pudiera considerarse general ${ }^{22}$.

Los Tratados prevén ocasionalmente la regulación de ciertas políticas por medio de alguna de las fuentes expuestas ${ }^{23}$; sin embargo, rige por lo general la indefinición del instrumento a adoptar ${ }^{24}$. En ciertas ocasiones se deja al arbitrio del legislador la promulgación de reglamentos o directivas ${ }^{25}$.

En cualquier caso, la existencia de múltiples fuentes en Europa origina particulares dificultades. El particular equilibrio institucional en la Unión Europea, que se deduce de las diferentes competencias que atribuye el Tratado al Consejo y a la Comisión en los artículos $211^{26}$ y $202 \mathrm{TCE}^{27}$, hace que los poderes legislativo y ejecutivo en Europa se encuentren imbricados. No sólo porque el Consejo disponga de poderes legislativos y ejecutivos, sino porque la propia Comisión, al ejercer sus competencias, puede incidir sobre las fuentes que elabora el Consejo. Ciertamente, cabe distinguir entre reglamentos de base y de ejecución, como hizo el Tribunal de Justicia de las Comunidades Europeas en su resolución Köster, de 17 de diciembre de $1970^{28}$. La preocupación por preservar el equilibrio institucional conduce a reconocer el principio jerárquico entre Derecho secundario y terciario. Mas tal distinción no procede realmente de una graduación jerárquica de los órganos de poder en Europa, pues estas disposiciones jurídicas pueden adoptarse tanto por el Consejo como por la Comisión, a través de un procedimiento simplificado. Además, el Tribunal de Justicia ha llegado a reconocer amplios poderes discrecionales a la Comisión en el ejercicio de sus facultades ejecutivas ${ }^{29}$. El reglamento de ejecución podría no encontrarse subordinado al reglamento de base, pudiendo incluso modularlo.

28 Y a partir de esta distinción cabe configurar una suerte de principio de legalidad en el orden europeo. Cfr. también la sentencia Alemania \&Comisión C- 240/90, que sin embargo confunde principio de legalidad con jerarquía.

29 STJCE 1 de Marzo de 1987, as. 279, 280, 285 y 286/84

30 LÓPEZ BASAGUREN, A, Constitución y Unión Europea: aporías en la integración comunitaria», GARCÍA HERRERA (dir), El Constitucionalismo en la crisis del Estado social, Zarautz: Argipalten Zebirtzua. Universidad del País Vasco, 1997, pág. 299

31 Si bien de la propia lectura del artículo 5 puede desprenderse no sólo el principio de las limitadas habilitaciones competenciales sino también la posibilidad de expansión de este nuevo orden a través de los propios objetivos que contempla el Tratado

32 En el contexto del análisis de los principios de las limitadas habilitaciones específicas y de subsidiariedad, observa LÓPEZ PINA cómo la inclusión de aquéllos en los Tratados no empece a «la naturaleza dinámica de una Comunidad Europea funcionalmente integrada y orientada a fines», «Del principio de subsidiariedad como límite al ejercicio de las competencias en la Unión Europea», Politeia. Número extraordinario en homenaje a don Manuel García Pelayo, Universidad Central de Venezuela, septiembre, 2000, pág. 2 En el mismo sentido se pronuncia BLECKMANN, Europarecht. Das Recht der Europäischen Union und der Europä̈schen Gemeinschaften, Carl Heymanns Verlag KG, pág. 280

33 ZAGREBELSKY, G, El Derecho dúctil. Ley, derechos y justicia, Madrid: Trotta, 1997 
normativo ${ }^{44}$; El artículo I-39 consagra la publicidad en el Diario Oficial de la Unión Europea de las leyes y las leyes marco (nueva denominación que adoptan, respectivamente, los reglamentos y las directivas) en cualquier caso; también la de los reglamentos europeos y las decisiones europeas que no indiquen destinatario o que tengan como destinatarios a todos los Estados miembros ${ }^{45}$. Inicialmente, el proyecto de Tratado presentado por la Convención a la Conferencia Intergubernamental de Roma incorporaba el Consejo Legislativo que unificaba la función legislativa del Consejo de Ministros (artículo I-23); ésta se convertiría así de hecho en la Cámara de los Estados; las sesiones de este Consejo serían públicas. La Conferencia Intergubernamental bajo presidencia italiana preveía suprimir este Consejo Legislativo y así se hizo finalmente en la posterior Conferencia Intergubernamental; se frenó así uno de los avances más significativos del proyecto de Tratado Constitucional presentado por la Convención. En cualquier caso, el Tratado finalmente resultante asegura la publicidad de las sesiones del Consejo cuando delibere y vote sobre un proyecto de acto legislativo (artículo I-24.6). También gozarán de publicidad las sesiones del Parlamento Europeo (artículo I-50.2).

El procedimiento de codecisión ha tendido a generalizarse, y así se ha expresado en la Convención sobre el Futuro de Europa ${ }^{46}$. El Tratado por el que se establece una Constitución para Europa prevé este procedimiento como el procedimiento legislativo ordinario, y sólo en los casos particulares específicamente previstos podrán regir procedimientos legislativos especiales (artículo 33, apartados 1 y 2 del tratado Constitucional).

\subsection{La CONCEPCiÓn Del Derecho EN EL Tratado POR EL QUE SE ESTABLECE UNA CONSTITUCIÓN PARA EUROPA}

El nuevo Tratado no parece alterar la concepción del Derecho que hasta ahora han tenido las instituciones europeas. Se mantiene el artículo 308 TCE en el artículo I-18, si bien se establecen como novedad ciertos mecanismos de control que pueden contener sus efectos ${ }^{47}$. El artículo I-3 mantiene la definición inicial de los objetivos de la Unión y el propio articulado del Tratado Constitucional, especialmente su Parte III donde regula las políticas,

34 LÓPEZ PINA, A. «Las tareas públicas en la Unión Europea», Revista de Derecho Comunitario Europeo n 4, 1998, . pág. 2

35 SCHOCH, F, Die europäisierung des verwaltungsrechtlichen Rechtsschutzes, Juristen Zeitung 3,3, 1995, págs, 22, 23

36 SCHOCH, F, Die europäisierung des verwaltungsrechtlichen Rechtsschutzes «, op. cit, pág. 26

37 BLECKMANN, A, Europarecht. Das Recht der Europäischen Union und der Europäischen Gemeinschaften, op. cit, pág. 205

38 Merced a este principio las normas europeas deben ser interpretadas y aplicadas en el sentido más propicio a los fines de la integración

39 BLECKMANN, A, Europarecht. Das Recht der Europäischen Union und der Europäischen Gemeinschaften, op. cit, pág. 205

40 GUTIÉRREZ GUTIÉRREZ, I, . «Un Orden Jurídico para Alemania y Europa» Teoría y Realidad Constitucional $\mathrm{n}^{\circ} 3,1999$, pág. 220. Un ejemplo de esta interpretación teleológica del tribunal puede encontrarse también en el campo del derecho medio ambiental de la Unión Europea, SCHOCH, F, «Individualrechtsschutz im deutschen Umweltrecht unter dem Einfluss des Gemeinschaftsrechø» Neue Zeitschrift für Verwaltungsrecht, $\mathrm{n}^{\circ} 5$ 1999, págs. 461 ss.

41 Cfr. PRECHAL, S, Directives in European Economic Law. A study of directives and their enforcement in national courts, Oxford: Clarendon Press, 1995 
de las directivas. La evolución de esta fuente del Derecho ofrece un claro ejemplo de la actividad conjunta, de un lado, del creador del Derecho y, de otro, del Tribunal de Justicia, para el logro de la mayor integración. La Comisión fomenta la promulgación de las denominadas directivas detalladas, el Tribunal de Justicia contribuye a que estas directivas tengan efecto directo. Esta doble actividad ha contribuido a desnaturalizar esta fuente del Derecho y a aproximarla al reglamento ${ }^{41}$.

\subsection{LOS PROCEDIMIENTOS DE PRODUCCIÓN DE LAS FUENTES}

El procedimiento de adopción de las fuentes del Derecho comunitarias depende del ámbito material (lo que se liga a las «políticas comunitarias»). El procedimiento general (artículo 250 TCE) prevé la participación del Consejo y de la Comisión, mas no del Parlamento Europeo. Ciertamente, el procedimiento de codecisión (artículo 251 TCE) permite participar a este órgano en la producción normativa, si bien en condiciones no asimilables a las de un parlamento democrático. Su excepcionalidad de principio ${ }^{42}$, atenuada por la cantidad de supuestos regulados en el Tratado por medio de este procedimiento ${ }^{43}$, le impide constituirse en el órgano central en la producción de normas jurídicas europeas. Por lo demás, no se prevén cauces para complementar la representación que encarna este órgano con el principio representativo que encarnan los parlamentos nacionales. Si bien el Parlamento Europeo goza de publicidad en sus actuaciones, cada una de las formaciones del Consejo de Ministros con capacidad legislativa negocia a puerta cerrada. Sólo se publican el Boletín Oficial de la Unión Europea los reglamentos, las directivas y las decisiones adoptados mediante el procedimiento de codecisión o aquéllos que estén destinados a todos los Estados miembros. Las demás directivas, así como las decisiones, surtirán efectos a partir de su notificación (artículo 254 TCE).

\section{REGULACIÓN DE LAS FUENTES EN EL TRATADO POR EL QUE SE ESTABLECE UNA CONSTITUCIÓN PARA EUROPA}

\subsection{LOS PROCEDIMIENTOS DE PRODUCCIÓN}

El nuevo Tratado generaliza la publicidad en la adopción de las decisiones con valor

42 Sólo cuando en la adopción de un acto se haga referencia a este procedimiento podrá aplicarse (artículo 251 TCE)

43 El Tratado de Amsterdam no sólo amplía los casos en los que ha de aplicarse este concreto proceso; simplifica además su procedimiento, al suprimir la tercera lectura (artículo 1, apartado 44, Tratado de Amsterdam). Las decisiones que afecten a la Unión Económica y Monetaria se realizan al margen del procedimiento de codecisión

44 Sobre la aportación de la publicidad para la legitimación de la ley, Cfr. ALZAGA, O, Derecho Político español según la Constitución española de 1978 I. Constitución y fuentes, tercera edición. Madrid: Centro de Estudios Ramón Areces, 2001, págs. 354, 355

45 Las demás decisiones se notificarán a sus destinatarios y surtirán efecto a partir de tal notificación 
dades concurrentes en la Unión Europea, esto es, al Parlamento Europeo y al Consejo. El denominado procedimiento legislativo ordinario (artículo I-34.1 y 2 del Tratado por el que se establece una Constitución para Europa) se orienta en esta dirección. El nuevo Tratado ha convertido los supuestos de indefinición del instrumento jurídico a adoptar en reservas de ley europea $^{53}$, o indistintamente de ley o ley marco europea ${ }^{54}$, mas no ha extendido la reserva de la reciente ley marco europea ${ }^{55}$

El nuevo Tratado pretende aquilatar el particular equilibrio institucional en la Unión Europea, que hacía que los poderes legislativo y ejecutivo se encontraran imbricados. Regula, como novedad, los denominados reglamentos delegados (artículo I-36). Las leyes y las leyes marco europeas podrán delegar en la Comisión la competencia para promulgar reglamentos delegados que completen o modifiquen determinados elementos no esenciales de aquéllos. Delimitarán de forma expresa los objetivos, el contenido, el alcance y la duración de la legislación. Pueden además determinar de forma expresa las condiciones de aplicación a las que estará sujeta la delegación. Los temores expresados en la Convención relativos al control de este instrumento normativo podrían verse salvados mediante la inclusión en este precepto de ciertas condiciones de vigencia a que pueda verse sujeta la norma delegada ${ }^{56}$. Podría asimilarse esta nueva fuente a los decretos legislativos de nuestro orden constitucional. Su fundamento reside en la necesidad de que el poder legislativo descargue su tarea normativa a favor del ejecutivo, que cuenta con medios más ágiles y con una mayor competencia técnica para hacer frente a las crecientes y complejas demandas objeto de regulación. La posibilidad de que estos reglamentos delegados puedan completar o modificar elementos de la ley o de la ley marco cuestiona sin embargo su asimilación a esta fuente. En cualquier caso, la garantía de que tal delegación haya de ser expresa, sobre elementos no esenciales de la legislación previa y sujeta a control, permite al poder legislativo mantener su centralidad en la producción normativa. A él le sigue correspondiendo, y con esta figura puede garantizarme, la tarea de dirigir o encauzar la innovación del ordenamiento jurídico.

Las decisiones europeas, reguladas en el artículo I-33, no se diferencian de las decisiones reguladas anteriormente en el artículo 249 TCE, mas que en una aclaración que se realiza en el nuevo Tratado: las nuevas decisiones europeas pueden designar destinatarios o no designarlos ${ }^{57}$. Cuando tuviera destinatarios, sería obligatoria sólo para ellos. La definición de la decisión europea es, en consecuencia, más amplia que la establecida en el antiguo Tratado, si bien conserva por lo demás idéntica naturaleza jurídica ${ }^{58}$. Se extienden así los supuestos en que puede aplicarse este particular instrumento jurídico, lo que no deja de tener importantes consecuencias en el ordenamiento jurídico europeo. Además, el Consejo Europeo puede adoptar decisiones europeas en los casos previstos expresamente en el

46 Cfr, entre otros, el debate de la Convención celebrado los días 12 y 13 de septiembre de 2002, CONV 284/02 y las Conclusiones del Grupo Simplificación, CONV 424/02

47 El apartado segundo de este precepto dispone que la Comisión, en el marco del procedimiento del control del principio de subsidiariedad, indicará a los parlamentos nacionales de los Estados miembros las propuestas que se hacen en este sentido. Además, en su apartado tercero, prohíbe que las disposiciones adoptadas en virtud de este precepto puedan conllevar armonización alguna de las disposiciones legislativas y reglamentarias de los Estados miembros en los casos en que la Constitución excluya tal armonización

48 El Tribunal de Justicia de las Comunidades Europeas pasa a denominarse Tribunal de Justicia europeo y el Tribunal de Primera Instancia Tribunal General de Instancia (artículo I-27) 
reproduce prácticamente los preceptos de los antiguos Tratados europeos. La naturaleza del Tribunal de Justicia, por lo demás, se configura en términos idénticos a la que configuran los Tratados europeos (artículo I-29 y subsección $5^{\text {a }}$ del Capítulo $2^{\circ}$ del Título IV de la Parte III de la Constitución: Del funcionamiento de la Unión, artículos III-353 a III-381). Más allá de ciertos cambios de denominación ${ }^{48}$, no prevé el Tratado por el que se establece una Constitución para Europa ningún precepto que limite la actividad del Tribunal. Ni siquiera se recoge Protocolo alguno sobre el Tribunal de Justicia que pudiera hacer mención a su extralimitación histórica y a la necesidad de poner coto a su activismo. Antes bien, el Tratado constitucional asume expresamente cierta jurisprudencia del Tribunal de Justicia, como el principio de primacía del Derecho europeo. Lo incorpora a su artículo I-6; dispone: «La Constitución y el Derecho adoptado por las instituciones de la Unión en el ejercicio de las competencias que le son atribuidas primarán sobre el Derecho de los Estados miembros.

\subsection{LAS FUENTES DEL DEREChO}

El Grupo IX de la Convención (Simplificación) propuso introducir un fundamento orgánico en el que introducir la jerarquía en el ordenamiento europeo ${ }^{49}$. El Tratado por el que se establece una Constitución para Europa distingue así tres niveles: actos legislativos, que son los antiguos reglamentos y pasan a denominarse leyes europeas, y las viejas directivas, que adoptan la denominación de leyes marco europeas (artículo I-33); en segundo término, los actos delegados, que se denominan reglamentos delegados (artículo I-36); y en tercer lugar los actos de ejecución, denominados reglamentos de ejecución o de decisión, que son actos de ejecución de los actos delegados o de los actos legislativos. Al igual que en el caso de los actos delegados, correspondería al legislador determinar si es preciso adoptar a escala de la Unión actos de ejecución de los actos legislativos o delegados y en qué medida (artículo I-35) ${ }^{50}$.

Los reglamentos y directivas, como ya hemos indicado, adoptan respectivamente, la nueva denominación de leyes europeas y leyes marco europeas ${ }^{51}$. Su regulación en el Tratado por el que se establece una Constitución para Europa (artículo I-33) es idéntica a la de los antiguos Tratados (artículo 249 TCE). Con su denominación clásica, se sitúan inmediatamente subordinados a la Constitución ${ }^{52}$. Para que estas figuras no desatiendan los requisitos formales de una noción de ley, deben vincularse a las instituciones que representan las legitimi-

49 CONV424/02, Convención europea. Simplificación, op. cit, págs. 12 y 18 a 23

50 No obstante, cuando el Grupo presentó sus conclusiones al Pleno de la Convención algunos oradores mostraron su inquietud ante la nueva gradación jerárquica, e insistieron en la importancia de prever en el Tratado Constitucional un mecanismo de call back a favor del legislador cuando éste recurriese al mecanismo de la legislación delegada

51 Las nuevas fuentes dejan de ser sólo fuentes del Derecho comunitarias para convertirse en fuentes del Derecho europeas; son aplicables, pues, a los tres pilares tradicionales de la Unión Europea, que el Proyecto de Constitución europea unifica. El pilar relativo a los asuntos de justicia e interior prevé numerosas reservas de leyes europeas o de leyes marco europeas (artículos III-170, III-171, III-172, III-173, III-176), el segundo pilar, relativo a la Política Exterior y de Seguridad Común mantiene sin embargo las previsiones de los antiguos tratados (artículos III-196, III-201)

52 Como observa Balaguer, el «intento de acomodar el sistema de fuentes a categorias constitucionales comienza con la creación de la ley europea y la ley marco europea», «El sistema de fuentes en la Constitución europea», Revista Española de Derecho Constitucional. 
a través de actos atípicos en reservas de ley europea o ley marco europea ${ }^{63}$. Pero mantiene también otros actos atípicos ${ }^{64}$ o los convierte en decisiones europeas ${ }^{65}$. Al no incidir el nuevo Tratado en la concepción del Derecho europeo, no parece posible la supresión de los actos atípicos no previstos expresamente en él.

\section{A MODO DE CONCLUSIÓN}

La nueva regulación prevista en el Tratado por el que se establece una Constitución para Europa es desigual; podría clarificar, al menos aparentemente, el sistema de fuentes europeo; aproximarlo así al propio del vigente constitucionalismo. Sin embargo, evidencia también una cierta confusión a la hora de regular las fuentes jurídicas. Al no incidir en la concepción que del Derecho tienen las autoridades europeas puede permitir la temprana frustración de los avances realizados. Por lo demás, la Conferencia Intergubernamental que sucedió a la Convención rebajó los progresos realizados inicialmente.

El nuevo Tratado introduce un fundamento orgánico en el que apoyar la jerarquía. De esta manera parece acercar el nuevo orden europeo a la tradición de nuestros Estados constitucionales. Podrá así, al menos en principio, asegurar la prevalencia de las distintas fuerzas sociales en el orden europeo a través de un baremo democrático. Las leyes y las leyes marco europeas gozan de una mayor proximidad al origen popular del poder que los reglamentos de ejecución o decisión, y así se refleja en la gradación jerárquica prevista en el Tratado Constitucional. Sin embargo, no prevé la subordinación de las decisiones europeas a las fuentes de carácter general. Extiende, por lo demás, los supuestos en que pueden aplicarse. Las decisiones europeas, como es conocido, son actos administrativos; al no encontrarse subordinados a fuentes regidas por el principio de legalidad el riesgo es evidente: la decisión microsectorial, con objetivos específicos y particulares, amenaza el principio de igualdad, en la misma medida en que subvierte el sentido jurídico y político del principio de legalidad; gobernar a través de actos administrativos es justamente el contrapunto del gobierno de las leyes.

53 Artículos I-53 (artículo 269 TCE), I-55 (artículo 272 TCE), III-49, III-76.13 (artículo 104.14), III- 79.5 (artículo 107.5 TCE), III-119 (artículo 161 TCE), III-120 (artículo 162 TCE), III-130.3 (artículo 175.3 TCE)

54 Artículos III-122 (artículo 12.2 TCE), III-123 (artículo 18.2 TCE), III-124 (artículo 19 TCE), III-144 (artículo 49 TCE), III-46.3, III-172 (artículo 93 TCE), III-68, III-210.2 (artículo 137.2 a) TCE), III-214.3 (artículo 141 párrafo tercero TCE), III-143, III-121 (artículo 42 TCE), III-179 (artículo 152 TCE), III-217 (artículo 133.2 TCE), III-223 (artículo 179 TCE), III-232 (artículo 190.4 TCE), III-310 (artículo 272 TCE), III-335

55 Reserva de ley marco europea se produce en los artículos III-23 (artículo 44 TCE), III-26 (artículo 47 TCE), III-32 (artículo 52 TCE), III-64 (artículo 94 TCE); únicamente lo aplica en un nuevo supuesto, no contemplado en el TCE, el artículo III-172 sobre normas mínimas relativas a la definición de las infracciones penales

56 Estas condiciones pueden consistir en las siguientes posibilidades: -El Parlamento Europeo o el Consejo de Ministros podrán decidir revocar la delegación—. El reglamento delegado sólo podrá entrar en vigor si el Parlamento Europeo y el Consejo de Ministros no han formulado objeciones en el plazo fijado en la ley o ley marco. A estos efectos, el Parlamento Europeo se pronunciará por mayoría de los miembros y el Consejo de Ministros lo hará por mayoría cualificada 


\section{Tratado constitucional (artículo I-34 apdo $3^{\circ}$ )}

El artículo I-33 del nuevo Tratado prevé el reglamento europeo como un acto no legislativo de alcance general que tiene por objeto la ejecución de actos legislativos y de determinadas disposiciones particulares del Tratado. Estos reglamentos los pueden dictar la Comisión, el Consejo de Ministros, e incluso el Banco Central Europeo (artículo I-35). La Comisión adoptará reglamentos europeos o decisiones europeas al efecto de llevar a término actos de ejecución; incluso el Consejo de Ministros puede dictar reglamentos en orden a llevar a cabo esta tarea ${ }^{59}$; pero ordinariamente serán los Estados Miembros los encargados. El artículo I-37 denomina a estos instrumentos dedicados a ejecutar disposiciones de Derecho europeo reglamentos europeos de ejecución o decisiones europeas de ejecución ${ }^{60}$. Introduce con ello un factor de confusión considerable. Podemos encontrarnos de nuevo ante actos de ejecución (decisión europea de ejecución) no subordinados a fuentes legales.

El nuevo Tratado contiene remisiones expresas a los reglamentos europeos; tanto a los que pueden ser adoptados por el Consejo de Ministros (artículos III-160, 163, 169, 183, 190.1 a), 201.2 a), 231.3, 240.3, 253, 260, 263, 332, 400, 412.2, 433), como a los que puede promulgar la Comisión (artículos III-166, 232). Ciertos reglamentos previstos expresamente se caracterizan por encontrarse subordinados a los actos legislativos de la Unión (así, por ejemplo, los previstos en los artículos III-160, 169, 187.4). Los reglamentos sometidos exclusivamente a la Constitución (que parecen ser la mayoría de los previstos en el Tratado Constitucional) ${ }^{61}$ podrían evocar los denominados reglamentos independientes. Lo que les caracterizaría es su producción en ámbitos en los que no existe normativa legal aplicable, pero sólo serían legítimos en tanto no contravinieran lo dispuesto en las leyes. Directamente infraordenados a la Constitución, estarían también vinculados a las fuentes legales, «pues definen su propia validez en relación con la ausencia de regulación aplicable a un determinado supuesto de hecho» ${ }^{62}$. Los reglamentos europeos, por lo demás, son susceptibles de ser aplicados directamente; pero también pueden imponer solo un resultado y dejar a los Estados la elección de la forma y los medios.

El Tratado Constitucional, por último, convierte la anterior regulación de ciertas políticas

57 La regulación de las decisiones, recogida en el artículo 249 TCE dispone que «La decisión será obligatoria en todos sus elementos para todos sus destinatarios». La nueva regulación, recogida en el artículo I-32 del nuevo Tratado dispone que «La decisión europea es un acto no legislativo obligatorio en todos sus elementos. Cuando en la decisión se designen los destinatarios de la misma, sólo será obligatoria para éstos». La única diferencia estriba en esta última aclaración, por lo demás recogida en la jurisprudencia anterior a esta regulación, que en nada modifica su naturaleza jurídica.

58 Esta decisión redefinida, como prevé el Grupo Simplificación, puede ser de especial utilidad en el ámbito de la PESC. La decisión sería así un instrumento flexible que podría aplicarse en múltiples casos, por ejemplo, para los nombramientos o para ciertas medidas en materia de competencia o de ayudas públicas.

59 Cuando se requieran condiciones uniformes de ejecución de los actos obligatorios de la Unión, o en casos específicamente justificados y en los previstos para la ejecución de la política exterior y de seguridad común (artículo I-36. 3 y 4 Tratado Constitucional)

60 Añade este artículo a la denominación establecida en el artículo I-32 reglamento europeo la de decisión europea de ejecución. Parecen ser dos instrumentos jurídicos idénticos que no se diferencian más que en su denominación.

61 No se prevé una subordinación expresa del reglamento a los actos legislativos de la Unión en los sigientes artículos: III - 14.3, 39, 52, 55, 58, 64, 75, 82.3, 95.2, 126.2, 127.3, 128, 138.3, 154, 161, 164, 224, 306, 318,339 
regular simplemente los objetivos a realizar dejando a las autoridades nacionales la elección de la forma y los medios. Resulta difícil entender esta posibilidad en una disposición de ejecución. Además, la multiplicidad de fuentes que ello podría generar tampoco parece orientar al Derecho europeo hacia una clarificación en sus contenidos ${ }^{69}$.

Los Estados miembros deben emplear al ejecutar Derecho europeo los reglamentos europeos de ejecución o las decisiones europeas de ejecución. A la luz de la vigente dogmática de la directiva, que asimila su incorporación al ordenamiento nacional a un acto de ejecución del Derecho comunitario, estas figuras jurídicas europeas serían idóneas para realizar la tarea. Mas se incidiría en la llamada «autonomía institucional». El propio Tratado Constitucional despojaría a los Estados de la facultad de elegir la forma y los medios a la hora de incorporar la ley marco $^{70}$

Es cierto que el Tratado por el que se establece una Constitución para Europa convierte ciertos actos atípicos en reservas de ley europea o de ley marco europea; pero matiene también otros actos atípicos. Por lo demás, la conversión de actos atípicos en decisiones europeas no resuelve el problema; nos encontramos de nuevo con actos administrativos no subordinados a fuentes de carácter general.

El nuevo Tratado no modifica la concepción que del Derecho han asumido las instancias comunitarias. La consecuencia en la regulación previa al Tratado Constitucional es el incremento de actos atípicos y la dilución de las características y la naturaleza de ciertas fuentes del Derecho europeas; el ejemplo paradigmático es el de la directiva. No parece así posible, en primer lugar, la supresión de los actos atípicos no previstos expresamente. Se mantendrá, en segundo lugar, la problemática acerca de la interpretación y aplicación de la directiva, ley marco conforme a la nueva regulación. Los problemas de las directivas detalladas y de la interpretación conforme seguirán constituyendo un problema en la dogmática de las leyes marco europeas.

Un progreso importante que ha introducido el nuevo Tratado es la generalización del procedimiento de codecisión, que adopta a su vez una nueva denominación más comprensible y adecuada al vigente constitucionalismo: procedimiento legislativo ordinario. Se asegura la publicidad de las fuentes europeas en el Boletín Oficial de la Unión Europea. Resultaba de la mayor importancia la creación de un Consejo Legislativo que dotara de unidad a la función legislativa del Consejo (artículo I-23 del proyecto de Tratado) y cuyas sesiones fueran públicas (artículo I-49 del proyecto de Tratado). Es así particularmente revelador que esta innovación no fuera finalmente aprobada; supone un retroceso

62 BALAGUER CALLEJÓN, F, Fuentes del Derecho Vol 1, Madrid: Tecnos, 1992

63 Son los supuestos previstos en los artículos III-115, III-120 III-130 y III-149. El artículo III-149 prevé que los anteriores programas marco utilizados en materia de investigación (artículo 166 TCE) se regulen a través de leyes europeas. El artículo III-219 convierte los programas de acción empleados en el medio ambiente (artículo 175 TCE) en leyes o leyes marco europeas. El artículo III-219.3 transforma las decisiones de aplicación del Fondo Social Europeo (artículo 148 TCE) en leyes europeas. El artículo III-224 prevé que las decisiones de aplicación relativas al Fondo Europeo de Desarrollo Regional se regulen a través de leyes europeas

64 El artículo III-179.2 mantiene las orientaciones generales en Política Económica y Monetaria (artículo 99 TCE); el artículo III-206.2 conserva las orientaciones en política de empleo (artículo 128 TCE); el artículo III247.2 mantiene las orientaciones relativas a redes transeuropeas (artículo 155 TCE)

65 Supuesto previsto en el artículo III-180 que prevé la regulación de las medidas adecuadas en Política Económica y Monetaria (artículo 100 TCE) por medio de decisiones europeas 
La nueva denominación que adoptan los reglamentos y las directivas en el Tratado por el que se establece una Constitución para Europa parece adecuada a la denominación clásica que en los órdenes constitucionales adquieren aquellas fuentes que por su proximidad al origen popular del poder se encuentran inmediatamente subordinadas a la Constitución. También parece acertado que los supuestos de indefinición del instrumento jurídico a adoptar hayan sido transformados por el nuevo Tratado en reservas de ley europea o indistintamente de ley o ley marco europeas. No se ha extendido sin embargo la reserva de la reciente ley marco europea; se pierde con ello la oportunidad de ampliar la aplicación de una fuente de Derecho europeo que puede adecuarse mejor al nuevo orden constitucional europeo ${ }^{66}$. Ello hubiera resultado de la mayor importancia, toda vez que, como hemos visto anteriormente, la fuente del Derecho más empleada por las instituciones europeas es el reglamento y no la directiva

Los reglamentos delegados quizá puedan solucionar el peculiar equilibrio institucional que hace que en la Unión Europea los poderes legislativo y ejecutivo se encuentren imbricados. Podrían asimilarse a los decretos legislativos de nuestro orden constitucional; cumplirían así una función política y jurídica de gran importancia en el nuevo orden ${ }^{67}$. No obstante, su regulación introduce un factor de confusión. Estos reglamentos delegados pueden complementar o modificar lo disputesto en las leyes o leyes marco. Con ello podrían adquirir fuerza activa y pasiva de ley. Al margen de lo confuso de su regulación ${ }^{68}$, el control de la legislación delegada será esencial para conseguir el efectivo funcionamiento de esta fuente jurídica.

El nuevo Tratado regula el reglamento europeo que subordina a las fuentes legales (artículo I-33); lo configura sin embargo como un acto de ejecución, por lo que dista de ser una fuente del Derecho. No puede asimilarse así a los reglamentos propios del Estado constitucional. Prevé una reserva de reglamento; se aproxima así el nuevo régimen constitucional europeo al sistema constitucional francés. No obstante, al extenderse esta reserva tanto a reglamentos dictados por la Comisión como por el Consejo, se prevé expresamente que un mismo órgano, el Consejo, siga desempeñando funciones legislativas y ejecutivas. El artículo I-37 prevé además dos concretas fuentes europeas para llevar a cabo la ejecución de Derecho europeo, los ya regulados reglamentos europeos de ejecución y las decisiones europeas de ejecución. Las reservas que se producen a lo largo del articulado permiten a su vez que la ejecución del Derecho europeo se lleve a cabo por cualquiera de estas disposiciones. Queda por aclarar si estas decisiones europeas de ejecución se encuentran subordinadas a las fuentes legales. De no ser así, se estaría permitiendo que actos de ejecución de disposiciones legales o de la propia Constitución, que deberían estar subordinados a aquéllas, pudieran regularse por medio de disposiciones que no cumplen tal subordinación. Estos reglamentos europeos, a su vez, pueden ser directamente aplicables o

66 Cfr. ALGUACIL GONZÁLEZ-AURIOLES, J, La directiva comunitaria desde la perspectiva constitucional, Madrid: Centro de Estudios Políticos y Constitucionales, 2004

67 Cfr. GUTIÉRREZ GUTIÉRREZ, I, Los controles de la legislación delegada, Madrid: Centro de Estudios Constitucionales, 1995

68 Para BALAguer, «esta especie de reglamento marco que se crea [...] tiene poco sentido desde el entendimineto habitual del reglamento y puede generar confusión entre lo aspectos competenciales y normativos», Revista Española de Derecho Constitucional Europeo, n², http://www.ugr.es/nredce/ 
69 Aparte de los problemas ya esbozados, observa BALAGUER cómo no se entiende el reglamento delegado en el supuesto de la leyes marco. «Justamente le está vedada la regulación de los elementos esenciales y tampoco puede invadir el ámbito competencial de los Estados, Revista Española Constitucional Europea, no2, http://wwwugr.es/nredce/

70 El parlamento nacional no podría, en ningún caso, participar en el proceso de incorporación de la ley marco europea. En el orden constitucional español cabe la posibilidad de que el Parlamento nacional participe en la incorporación merced al artículo $93 \mathrm{CE}$, si bien sus posibilidades de acción se han visto reducidas merced a la propia práctica constitucional. Su participación, en cualquier caso, sería obligada cuando el objeto de la ley marco afectara a materias sometidas en el orden interno a reseva de Parlamento. 
considerable mantener la vigente situación por la que cada una de las formaciones del Consejo de Ministros (Agricultura, Transportes, Finanzas...) goza de capacidad legislativa de forma autónoma ${ }^{71}$.

68 Las críticas más fuertes al Consejo Legislativo, aceptadas por 23 de los 25 Gobiernos que discutieron el Proyecto de Tratado Constitucional en la Conferencia Intergubernamental bajo presidencia italiana (todos salvo Alemania y Portugal) procedieron de los ministros de los diferentes ramos, que vieron en este Consejo una pérdida de su poder, pues ya no podrían legislar en sus Consejos Sectoriales. El entonces artículo I-23.1, no aceptado por la CIG, disponía: «la representación de cada Estado miembro correrá a cargo de uno o dos representantes más de rango ministerial cuyas competencias correspondan al orden del día del Consejo de Ministros» 
